\title{
PERCEPÇÃO DOS ALUNOS DA FACULDADE DE VIÇOSA - FDV EM RELAÇÃO À EDUCAÇÃO AMBIENTAL
}

Henrique de Andrade Cenachi - henrique.cenachi@gmail.com

Faculdade de Viçosa

Juliana Provenzani de Almeida - juprovenzani@ yahoo.com.br

Faculdade de Viçosa

Rodrigo Guimarães Chaves-rodrigoguimaraeschaves@ hotmail.com

Faculdade de Viçosa

João Carlos Lima Soares- joaoclima04@gmail.com

Faculdade de Viçosa

Ricardo Oliveira - ricardovt08@ yahoo.com.br

Faculdade de Viçosa

João Batista de Oliveira Junior - junim2312@yahoo.com

Faculdade de Viçosa

Johnny Souza Rodrigues - johnnytoshiba@ hotmail.com

Faculdade de Viçosa

Patrícia da Silva Santos - patriciasantos234@ gmail.com

Faculdade de Viçosa 


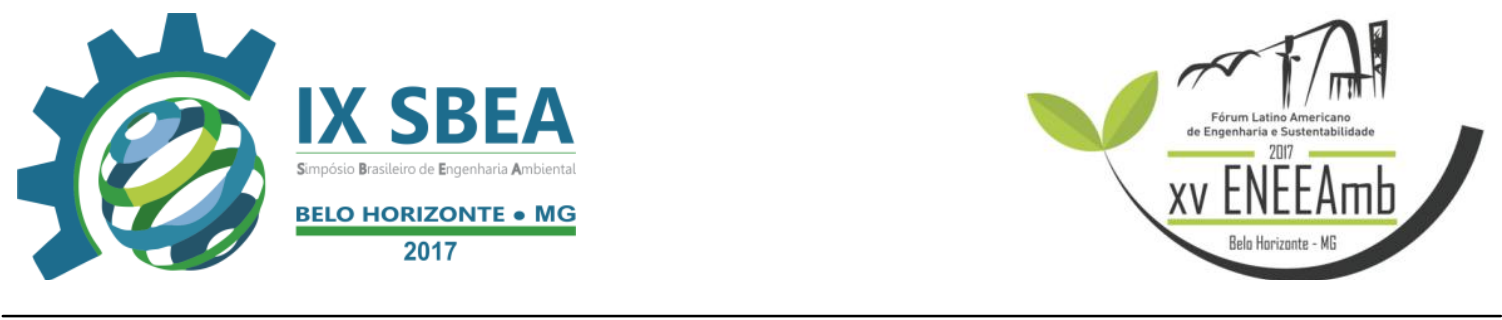

\section{RESUMO}

A temática ambiental se tornou um dos principais assuntos da atualidade devido aos grandes problemas relacionados ao meio ambiente. A educação ambiental tem como objetivo a disseminação de ideias positivistas em relação aos processos, das quais os indivíduos agem em prol da conservação do meio ambiente. A percepção ambiental possui grande relevância para o entendimento das inter-relações homem e o ambiente.

O trabalho teve como objetivo avaliar a percepção dos alunos da Faculdade de Viçosa - FDV em relação à educação ambiental. Para essa avaliação foi criado um questionário semi-estruturado com 21 perguntas entre questões abertas e fechadas. Esse questionário foi aplicado a uma amostra de 140 estudantes de graduação. As perguntas tinham como objetivo analisar o perfil dos graduandos assim como o conhecimento sobre temáticas ambientais e da importância desses conhecimentos na sua formação acadêmica. Após analises concluímos que grande parte dos graduandos possui uma boa percepção, mas que mesmo assim é necessário um maior envolvimento nas temáticas ambientais.

Palavras-chave: Educação Ambiental, Percepção Ambiental, Sustentabilidade

\section{INTRODUÇÃO/OBJETIVO}

A temática ambiental faz parte das diferentes discussões e preocupações da sociedade atual. O ambiente acadêmico se torna propulsor para a construção e divulgação de conhecimentos, participando assim da estruturação de uma sociedade mais consciente e sustentável.

Entende-se por educação ambiental os processos por meio dos quais o indivíduo e a coletividade constroem valores sociais, conhecimentos, habilidades, atitudes e competências voltadas para a conservação do meio ambiente, bem de uso comum do povo, essencial à sadia qualidade de vida e sua sustentabilidade (PNMA, 2017).

A crítica aos modelos de desenvolvimento econômico nocivo ao meio ambiente apresenta-se centrais em vários discursos que fundamentam a Educação Ambiental (DAS, 2000). 


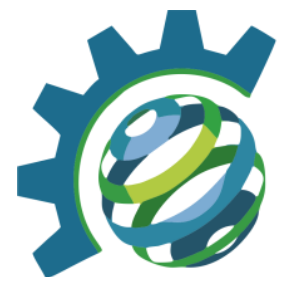

Segundo Reigota (2001), a educação ambiental propicia o indivíduo participação no âmbito social, político e econômico, devendo estar orientada para a comunidade com a participação ativa na resolução dos problemas.

O estudo da percepção ambiental é de fundamental importância para que possamos compreender melhor as inter-relações entre o homem e o ambiente, suas expectativas, anseios, satisfações e insatisfações, julgamentos e condutas (FERNANDES, 2004).

Este trabalho teve como objetivo avaliar a percepção ambiental dos alunos da Faculdade de Viçosa (FDV) a respeito da educação ambiental, verificando se os mesmos têm conhecimento sobre os conceitos ambientais, bem como sua importância nas atividades do cotidiano e a aplicação em sua área de formação profissional.

\section{METODOLOGIA}

A Faculdade de Viçosa foi a primeira instituição particular de nível superior do município de Viçosa-MG. Fundada no ano de 2001, atualmente possui 391 alunos, distribuídos em sete cursos de graduação (Tabela 1): Engenharia de Produção (18,67 $\%)$, Engenharia Ambiental (7,42 \%), Administração (15,86 \%), Pedagogia (12,53 \%), Sistemas de Informação (8,69 \%), Publicidade e Propaganda $(8,95 \%)$ e Educação Física $(27,88 \%)$.

Tabela 1 - Cursos oferecidos pela FDV e suas respectivas quantidades de estudantes.

\begin{tabular}{|l|c|c|}
\hline \multicolumn{1}{|c|}{ Cursos } & Quantidade de alunos & Porcentagem de alunos \\
\hline EngenhariaAmbiental & 29 & $7,42 \%$ \\
\hline Engenharia de Produção & 73 & $18,67 \%$ \\
\hline Educação Física & 109 & $27,88 \%$ \\
\hline Sistema de Informação & 34 & $8,69 \%$ \\
\hline Administração & 62 & $15,86 \%$ \\
\hline Publicidade e Propaganda & 35 & $8,95 \%$ \\
\hline Pedagogia & 49 & $12,53 \%$ \\
\hline TOTAL & 391 & $100 \%$ \\
\hline
\end{tabular}




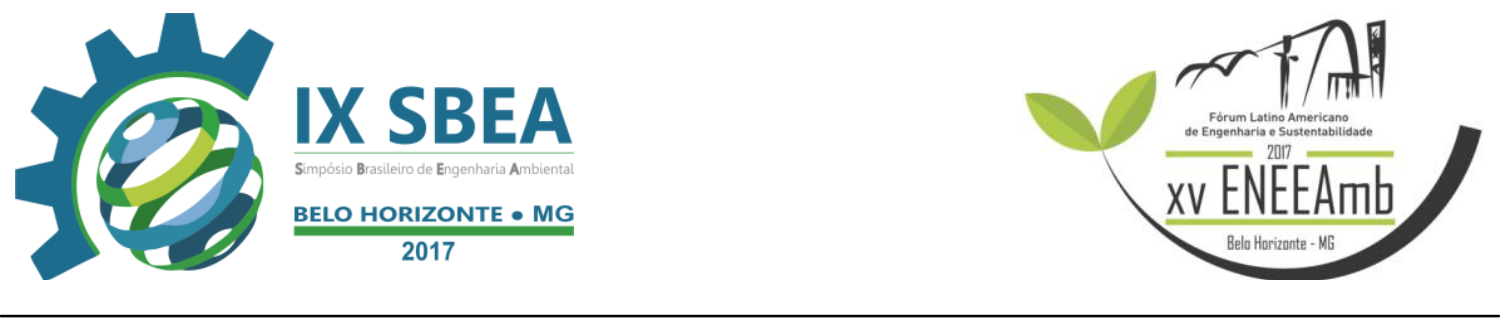

Para a avaliação da percepção foi elaborado um questionário semiestruturado que foi aplicado em uma amostra de 140 estudantes (Figura 1). Foi adotado como critério de exclusão a não participação dos autores deste trabalho neste estudo.

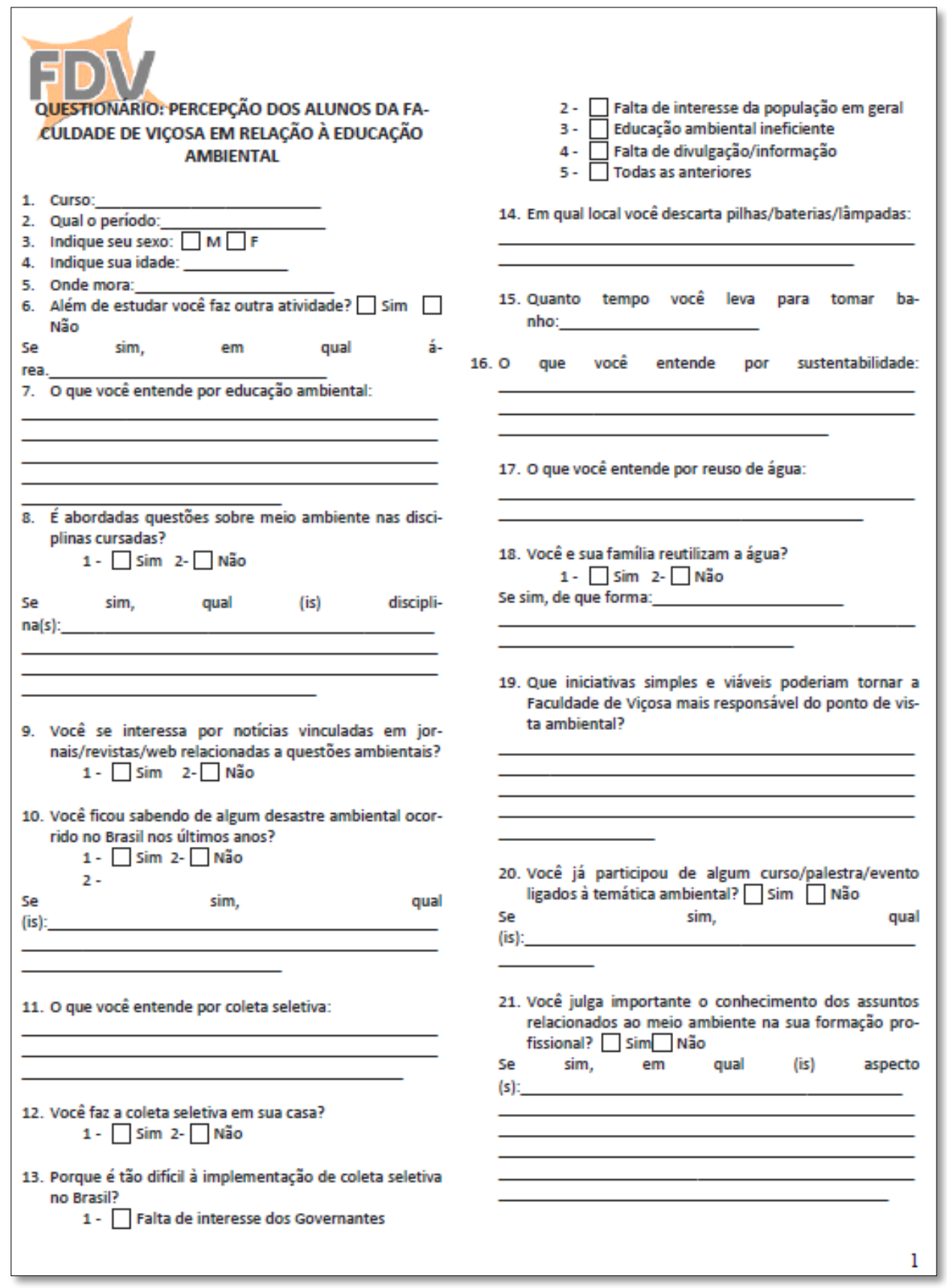

Figura 1: Questionário aplicado aos estudantes da FDV 


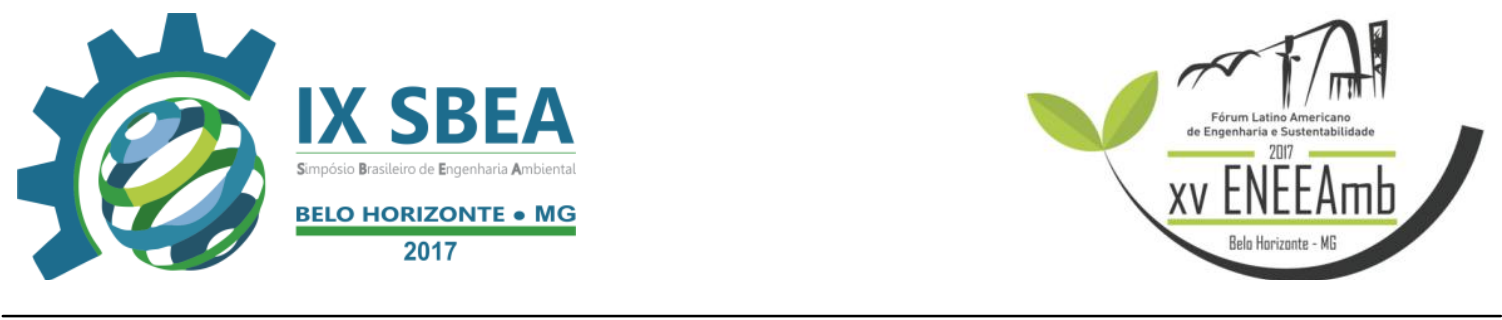

Após a coleta de dados foram realizadas análises estatísticas descritivas para as questões abertas, agrupando as respostas que mais apareceram e calculando seus percentuais. Nas questões fechadas realizamos o teste do $\chi^{2}$ para determinar se existe diferença estatística entre os dados coletados e os dados esperados, com nível de significância $5 \%$. Com base no teste foi verificado se existe diferença estatística entre as frequências observadas e as frequências esperadas. Para isso trabalhamos com duas hipóteses: hipótese nula e a hipótese alternativa. A hipótese nula ocorre quando as frequências observadas não são diferentes das frequências esperadas, não existindo diferenças entre as frequências. Já a hipótese alternativa as frequências observadas são diferentes das frequências esperadas, portanto existe diferença entre as frequências. Para a tomada de decisão foi observado a seguinte ideia:

- Se $\chi^{2}$ calculado for $\geq \chi^{2}$ tabelado, rejeita-se Ho.

- Se $\chi^{2}$ calculado for $<\chi^{2}$ tabelado, aceita-se Ho.

\section{RESULTADOS E DISCUSSÃO}

Em relação ao perfil dos estudantes que responderam ao questionário, 54,29\% são do sexo masculino, 45,71 são do sexo feminino (Figura 2). Os entrevistados tem faixa etária entre 19 a 25 anos que representaram 65,7\% do total, de 26 a 33 anos com $29,3 \%$ e de 34 a 58 anos com 5\%. Do total de $100 \%$ de entrevistados, $72,14 \%$ declararam conciliar o trabalho com os estudos, os demais 27,86 apenas estudam (Figura 2). Foi demonstrado que 67,2\% dos alunos residem em Viçosa e os demais $32,9 \%$ são de outras cidades vizinhas. 

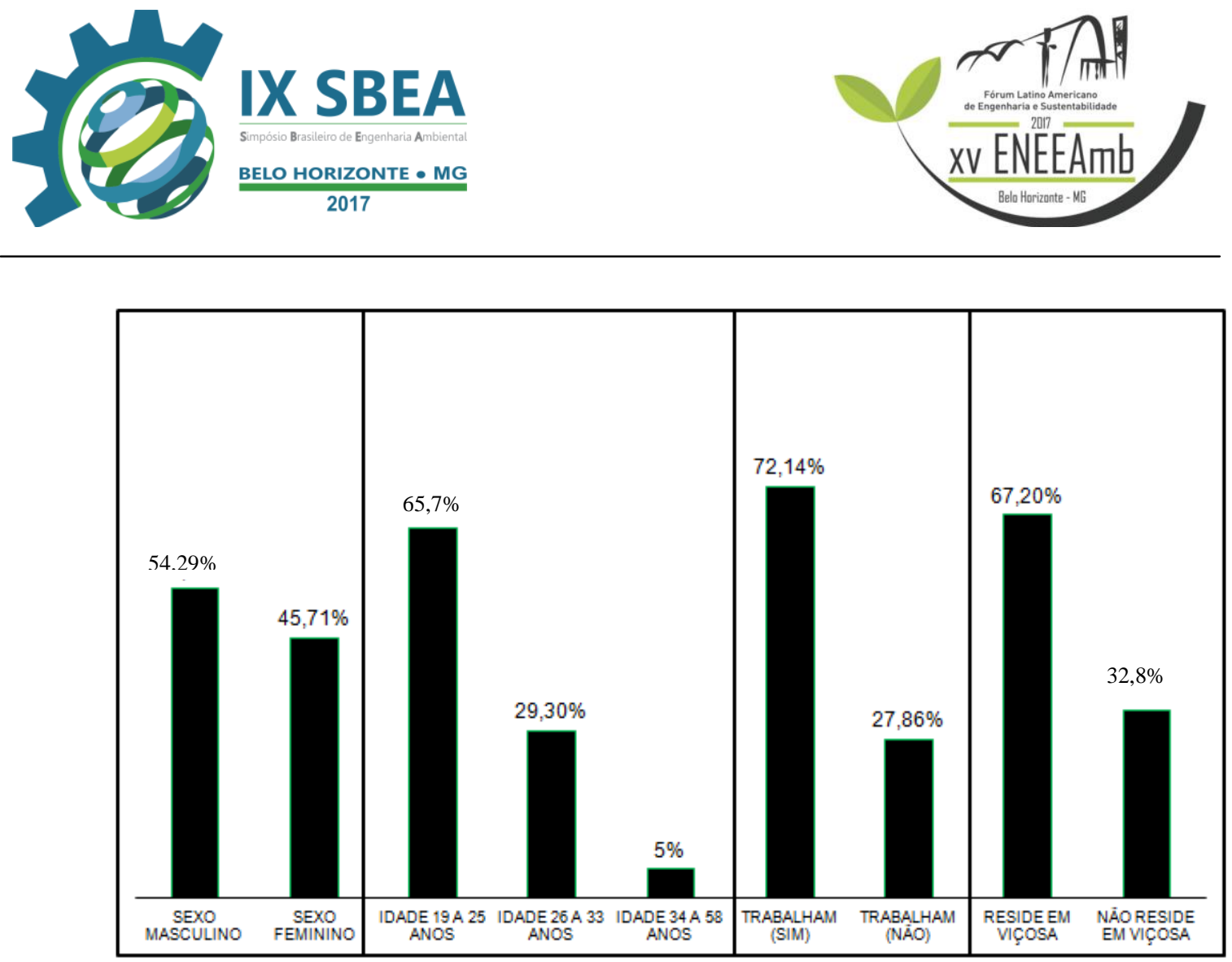

Figura 2: Perfil dos estudantes da FDV que responderam ao questionário sobre percepção ambiental.

Com base no teste de $\chi^{2}$ feitas nas questões fechadas $(8,9,10,12,18,19,20$ e 21$)$ obtemos os seguintes resultados gerais para os cursos, $(\mathrm{P}=0,05): 57,14 \%$ dos dados ocorreram diferença estatística entre os dados observados e os esperados. Já 42,86\% não ocorreu diferença significativa entre os dados.

O estudo demonstrou que $81,95 \%$ dos estudantes da Engenharia ambiental estão envolvidos com o meio ambiente como de esperado, seguido do curso de Pedagogia com 75,39\%, em sequencia temos a Engenharia de Produção com 69,48\%, Publicidade e Propaganda com 61,22\%, Administração com 60,98\%, Sistemas de Informação com 54,08 e por último temos o curso de Educação Física com 47,76\%, conforme demonstrado na Figura 3. 

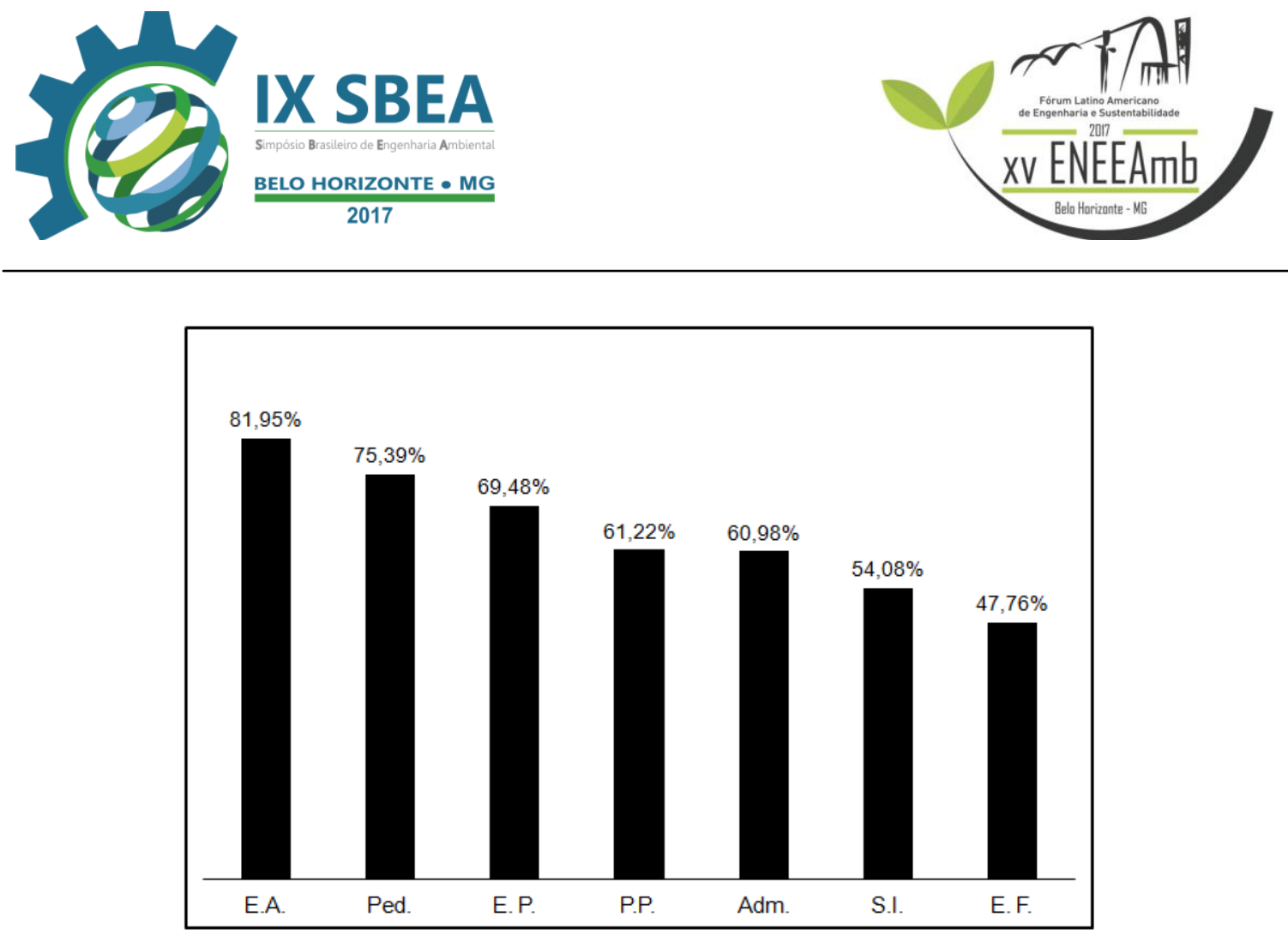

Figura 3: Percepção dos alunos da FDV em relação ao meio ambiente.

E.A. = Engenharia Ambiental; Ped.= pedagogia; E.P. = Engenharia de produção; P.P.= Propaganda e Publicidade; Adm.= Administração; S.I. = Sistemas de Informação; E.F.= Educação Física.

Em relação ao conceito de educação ambiental, $65.71 \%$ dos estudantes entrevistados, educação ambiental significa preservação do meio ambiente, $11.43 \%$ define como, informar e ensinar assuntos do meio ambiente, $11.43 \%$ não souberam responder e $11.43 \%$ como muitas outras definições.

Em relação ao descarte de pilhas e baterias, $62,86 \%$ dos estudantes descartam no lixo comum, $30 \%$ descartam corretamente, $5.72 \%$ não souberam responder e $1.42 \%$ dizem enterrar no solo.

$\mathrm{Na}$ definição de sustentabilidade, $35 \%$ dos entrevistados definiram sustentabilidade como sendo a preservação do meio ambiente visando o futuro, $25 \%$ dos estudantes definiram como: Utilizar os recursos naturais de forma sustentável, $23 \%$ não souberam responder, e 17\% definiram como sustentabilidade como, ser sustentável, produzindo de forma consciente.

$\mathrm{Na}$ definição de coleta seletiva $80 \%$ dos estudantes definiram coleta seletiva como a separação dos resíduos em categorias, 8.58\% como reciclagem dos resíduos, $5.71 \%$ não soube responder, $5.71 \%$ como diversas outras respostas. 


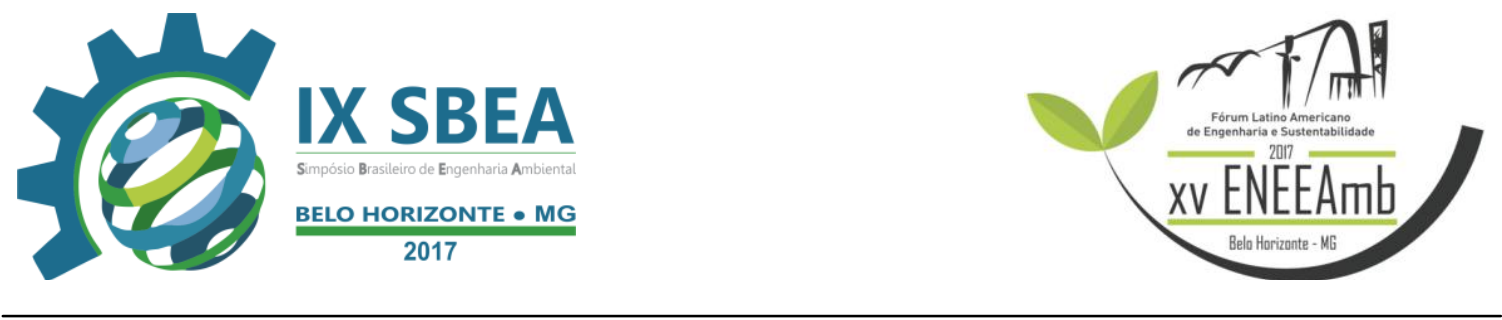

Com iniciativa simples e viável poderiam tornar a FDV mais responsável do ponto de vista ambiental, $72.14 \%$ dos alunos que responderam o questionário citaram a colocação de lixeiras para coleta seletiva, coleta de água da chuva para reuso nos banheiros e demais locais e a realização de palestras com o objetivo de conscientização ambiental como iniciativas a serem implantadas na Faculdade de Viçosa assim como a melhoria no curso de Engenharia Ambiental. O restante $27.86 \%$ não souberam responder.

\section{CONCLUSÕES/RECOMENDAÇÕES}

Percebe-se que é necessário o envolvimento de todos os cursos e estudantes na temática ambiental a fim de proporcionar um ambiente mais sustentável, já que 88,57\% vê a importância dos conhecimentos ambientais na sua formação profissional (Figura 4). Já em relação à percepção ambiental, 64\% dos estudantes entrevistados possuem uma boa percepção em relação à educação ambiental, os demais $36 \%$ não possui uma boa percepção, sendo necessário um maior envolvimento com a temática (Figura 5). Os estudantes reconhecem a necessidade da implantação de ações envolvendo a temática ambiental no espaço da FDV.

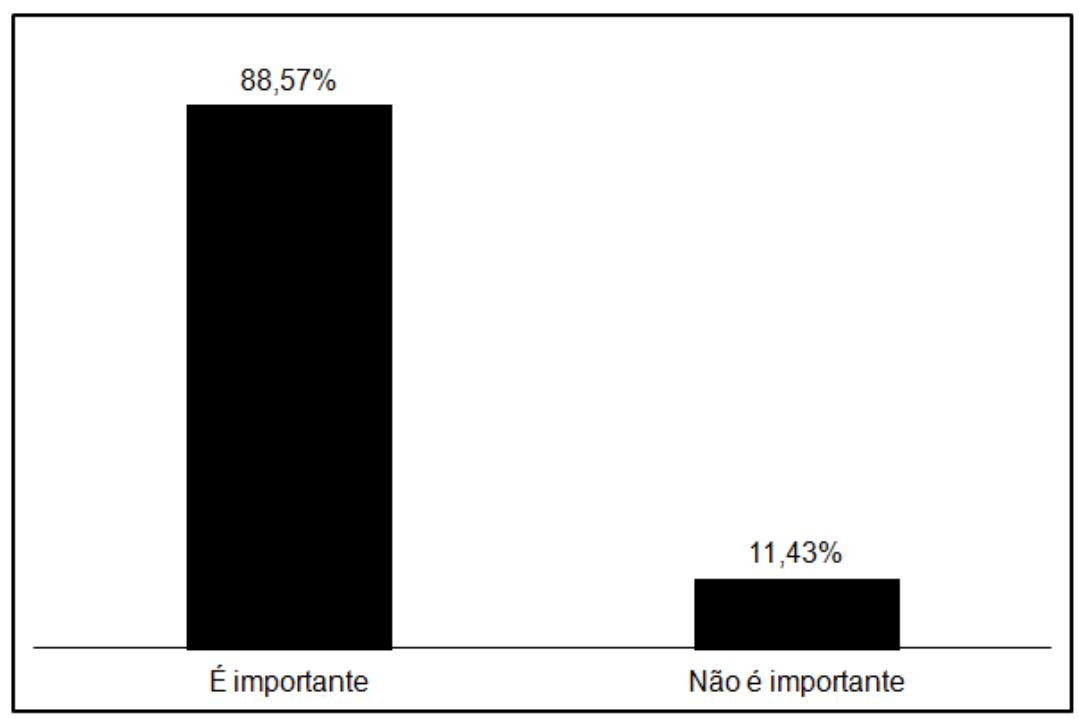

Figura 4: Porcentagens de estudantes da FDV que consideram importante os conhecimentos ambientais na sua formação profissional. 


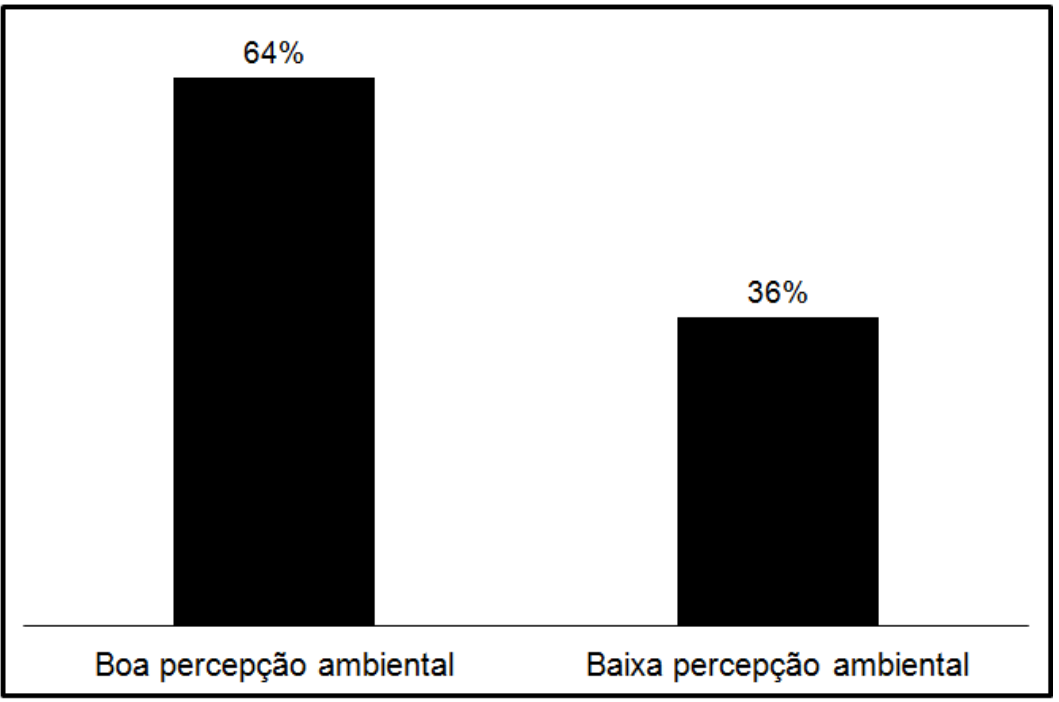

Figura 5: Porcentagens de estudantes da FDV com boa e baixa percepção ambiental.

\section{REFERÊNCIAS BIBLIOGRÁFICAS}

DAS, O. EXERCÍCIO. Educação ambiental. Revista Brasileira de Ciências Ambientais-número, v. 7, p. 28, 2000.

FERNANDES, Roosevelt S. et al. Uso da percepção ambiental como instrumento de gestão em aplicações ligadas às áreas educacional, social e ambiental. Encontro Nacional de Pós-Graduação e Pesquisa em Ambiente e Sociedade, v. 2, p. 1-15, 2004.

PNMA - Política Nacional do Meio Ambiente, Conceitos de Educação Ambiental. Disponível em: < http://www.mma.gov.br/educacao-ambiental/politica-de-educacaoambiental > Acesso em 20 de Maio de 2017.

REIGOTA, Marcos. O que é Educação Ambiental. Coleção Primeiros Passos. São Paulo: Ed. Brasiliense, 1994. 